knowledge of the activity of soil fungi comes from dilution-plating techniques, the limitations and merits of which, as well as those of alternative methods, are discussed in detail. All workers recognize that the traditional methods are highly selective, little able to discriminate between passive and active states of the organisms under study; hence the attempts to supplement plating techniques with visual microscopic methods, difficult as these are with an opaque medium such as the soil. Slowly we are gaining knowledge about the presence and mode of life of Basidiomycetes in the soil. It is even possible that a future book on the ecology of soil fungi would be mainly about the Basidiomycetes and Actinomycetes instead of the moulds which occupy the centre of interest at present.

Despite the unusually abundant misprints (not even insertion of the customary accents would remove the odd appearance of some passages in French), the large amount of original research presented here, with reviews of progress and methods, makes this a valuable and stimulating work.

P. H. GREGORY

\section{ILLUSTRATIONS OF FUNGI}

\section{Iconographia Mycologica}

By $\mathrm{O}$. Verona and T. Benedek (Mycopathologia et Mycologia Applicata, Volumes XI, XII, \& XIII). (I) Plates $A 1-18 ; B 1-10 ; C 1-18 ; D 1-4$. (II) Plates $A 19-46 ; B 11-23 ; C 19-25 ; D 5-6$. (III) Plates $A 47-84$; $C 26-33 ; D 7-10$. (Den Haag : Uitgeveij. Dr. W. Junk, 1959-60.)

$\mathrm{T}$ HREE supplements to the journal Mycopatho. logia et Mycologia A pplicata haverecently appeared from the pens of $O$. Verona, plant pathologist, and T. Benedek, merlical mycologist, under the title Iconographia Mycologica. These supplements consist of a series of folded sheets each containing drawings of characteristic features and a brief description of one or more selected genera of fungi. It is stated that the sheets are separate so that the owner has a choice in the manner in which he decides to arrange the collection. In fact, two systems of classification are given, one strictly orthodox and taxonomic; the other into the four categories: saprophytes, plant parasites, animal parasites and industrially important fungi. As a system of filing, this second arrangement would soon become impossible since some genera, for example, Aspergillus, fall into at least three of the four categories. Therefore the taxonomic system of filing is the only one that could be useful.

What, then, is the advantage in a loose-filing system here? It does allow additions to be fitted into the collection as these appear, but this is a dubious advantage since, if the rate of appearance of additions continues at a high level for long, the work as a system of identification is going to be incomplete and useless for just that long. If it is soon complete and up to date, then I see no advantage over the preparation of a complete book published at one time and ready for use, and in which the occasional minor change can easily be entered in hand by the owner. It seems, then, as though the work is not intended to assist in identification.
This supposition is supported by the fact that there are no keys to groups, and while in some genera some species are mentioned, in others no specific epithet is given. Moreover, there are no references to works by which specific identity could beconfirmed. One is left with the single conclusion that the main use for the loose-filing system is that sheets can be taken out as wanted with the aim of demonstrating or illustrating some point, presumably to an undergraduate class. The sheets here, then, serve the same functions that used to be performed by lectureroom wall charts and diagrams. It is doubtful that they perform these functions better for being smaller and monochromatic.

In fairness, it should be stated that the standard of drawing here is considerably higher than that found in illustrations to the more usual works of general identification such as Gilman's Manual of Soil Fungi and Barnett's Imperfect Fungi, but it is not so high as that which one has become accustomed to from the type of Commonwealth Mycological Institute publication issued under the names of $\mathrm{E}$. W. Mason and S. J. Hughes, from which, incidentally, many of the illustrations in the present supplements appear to be taken.

DAVID PARK

\section{HURRICANES}

\section{Atlantic Hurricanes}

By Gordon E. Dunn and Banner I. Miller. Pp. $\mathrm{xx}+326$. (Baton Rouge: Louisiana State University Press; London: Interscience Publishers, Ltd., 1960.) $75 s$.

THIS book has been written for the layman. The authors say that it is desirable he should have some meteorological background, and indeed already at the beginning of the second chapter he will encounter streamlines, contour lines and isotachs (should he feel at a loss, he can refer to a glossary of terms in an appendix), and then easterly waves and the Intertropical Convergence Zone. Still, his enthusiasm may have been stimulated by the first chapter, an eye-witness account of one of the most intense hurricanes of this century, and it is better that he should come to feel that his background could be improved than that the authors underestimate him.

The book continues as a well-illustrated, nonmathematical and very interesting account of practically all that is known about hurricanes and the related hazards of storm floods and tide surges, including how to prepare for, and ride out, these disasters. It becomes evident how much their study is now in the hands of American scientists, and in particular how the modern techniques of radar and reconnaissance by aireraft, and doubtless soon also by satellite, are being developed under the impetus of the National Hurricane Research Project, in which the authors work. It seems a far cry from the days, more than a century ago, when Englishmen took a leading part in the study of tropical storms. It may be said that the Americans have a special interest: each year they suffer a hundred million dollars' worth of damage from hurricanes, a sum equivalent to several times the expenditure on the entire meteorological service of Britain. But similar storms in the Bay of Bengal last Oetober drowned at least 